\title{
Determinants Of Social Exclusion: A Sociological Analysis Of Pakistani Women
}

\author{
Fauzia Maqsood \\ \& \\ Mohammad Nizamuddin \\ Department of Sociology \\ University of Gujrat
}

\begin{abstract}
The current study, "Effects of Socio-cultural Exclusion and Community Level factors on Reproductive Health Behavior of Pakistani women" was predicated on the household survey. By using probability sampling, primary data for this study was collected from five villages and one urban community through administering individual and community level survey questionnaire. The data was gathered by interviewing 622 ever-married women in both rural and urban areas in Kasur and Lahore district respectively. The present research focuses on the socio-economic determinants of social exclusion of women living in rural and urban areas of Pakistan. It was assumed that social exclusion of women is prevalent and it's predicated on dominant-subordination relationship of men and women. This relationship is assumed as commonly accepted amongst the various social strata of Pakistani society. A multitude of factors have come to play their respective roles in determining this dominant-subordination relationship that further anchors social exclusion of women from the mainstream social reconstruction program and regeneration of society on egalitarian determinants of power relations. Social exclusion can be measured through different benchmarks, it was measured by taking into account the level of participation of women in main socio-economic stream of life. Various indicators were identified to measure social exclusion of women namely: consultation in decision making process, political participation, participation in religious activities, and access to health services and right to cast votes during electioneering process.
\end{abstract}

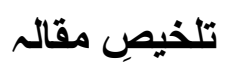

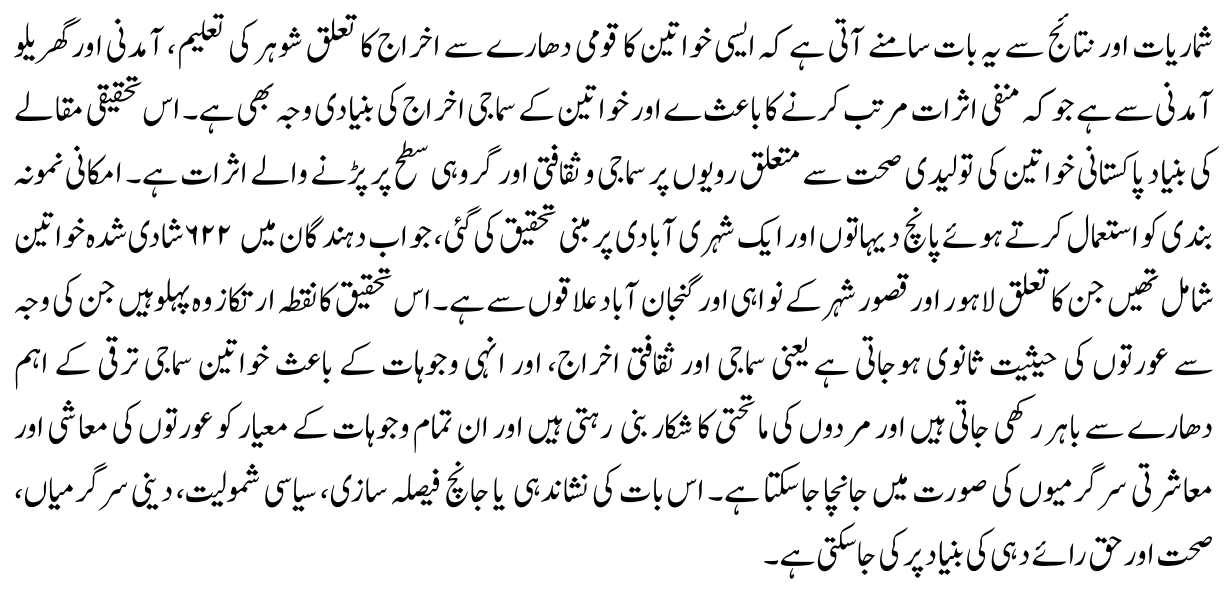


Key Words: Social exclusion, Determinants, Dominant-subordination, Patriarchy

\section{Introduction}

It has long been debated that Pakistani society is a patriarchal society where social relations seem to be tilted in the favor of male members of the family. Women seem to be discriminated within the categorization of gendered relationship. In a traditional society, gender plays an important role in determining dominant-subordination relationship. Many of the decisions concerning women's life are taken by the male members of the household. Women themselves may not be allowed to decide what they want to do. Similarly, women's participation in various aspects of life is restricted due to male dominance that results in the social exclusion and marginalization of women from the social life. Social exclusion has been defined as lack of access to various institutions of the society and to the basic levels of education, health and financial well-being that are essential to have access to those institutions (Burchardt, 2000). It is defined as the processes that exclude certain groups from full participation in social, cultural and political life of societies (Narryan, 1999). Many experts have argued that social exclusion is an inevitable result of inequality in society (Byrne, 2000) (Barry, 2002).

It incorporates a process by which certain categories or identified groups are consistently deprived because they are persistently discriminated against on the predication for their specific identifications, i.e. competition, ethnic-orientation, belief, sex, caste, age, impairment, HIV position, migrant position or their location. Exclusion is rampant in such situation as it happens in public organizations, such as the legislation or health facilities or educational institutions, as well as social organizations like the family. In this exclusive set-up, women are often omitted todistant non-urban areas and downtown slums, where it is difficult to sign up in decision-making and services for general access. However, social exclusion is also context-specific idea, which features how different deprivations (e.g. deficiency of employment, deficiency of governmental voice) can substantiate each other and impact a particular team or category of individuals through both official and casual programs. In Pakistani society, it is generally believed that women are also categorized as the exclusive group (Khan, 2010).

As it has been mentioned before that Pakistani society is a traditional society, therefore, due to conventional used patriarchy and architectural inequality, women become reliant on men. They rely on their fathers and brothers first and then on their spouses. Even in latter part of their lives, they rely on their own children for their sustenance. Various studies indicate that during upbringing period, boys are given more opportunities to have freedom, access to decision making and mobility whereas girls are restricted within the domestic sphere (Mensch., 2003). Thereasons of this restriction on girls' mobility are social taboos related to girls' protection and sanctity (Brady, 2003) (Colom, 2004) and that resulted into social exclusion of girls from various fields. 
Poverty and gender discrimination have been analyzed as potential risk factor of social exclusion. The analysis of gender discrimination has been the focus of attention and understood in terms of social relations and institutional dynamics. Social exclusion explained in terms of gender discrimination (Jackson, 1999) (Kabeer, 2000). Some other studies have examined that lack of financial resources leads to social exclusion from public and private services, from social relations and activities, and from social support (Gordon, 2000) (Howarth, 1999) (Robinson, 1998) (Room, 1995). Similarly, various other researches indicated various forms of social exclusion of women for instance limited peer networks (Amin, 2002), less social mobility and freedom (Erulkar, 2004) (Santhya, 2003) limited access to media and other sources of information (Amin, 2002) (Erulkar, 2004) and lower educational attainment (Mensch, 2005). This limited access, restricted mobility and constrained networking in social interaction make them incapacitated to have equal footing with their spouses when they get married (Clark, 2006) (Mensch, 1998). Due to lack of egalitarian profile in household women continue to have less freedom of movement (Amin, 2002) less autonomy and decision making authority in household and reproductive decisions (Santhya, 2003) and, in some settings, increased risk for gender-based violence (Kishor, 2004) sexually transmitted infections, and HIV infection (Clark, 2006). This situation made women further poor, which adversely affects their dependents and the next generation.

It is also observed that social exclusion of women varied from area to area. Particularly in rural areas women are highly excluded as compared to urban areas. Moreover, it was also observed that in those household women are less excluded where men have a relatively progressive mindset and liberal attitude towards women. Therefore, in present study an attempt is made to find out whether with reference to husband's education, occupation and household income is there any difference between levels of social exclusion of women.

\section{Conceptual Frame Work}

The present paper is developed on the conceptual framework of patriarchy, domination and social exclusion of women. It is based on the assumptions that in patriarchal structures male are dominated and enjoy more power and, thereby, restricted women's robust inclusion in socio-economic main stream of society to maintain status-quo. Social exclusion is a process in which powerful section of society does not provide equal opportunities to other and excludes the latter from full participation in development process. It is argued that in patriarchal system this dominant group is male-dominated. Although there have been discussions in the feminist movement whether it is correct to call the system of male dominance a patriarchal system. 'Patriarchy' literally means the rule of fathers. But today male dominance goes beyond 'rule of fathers' it includes the rule of husbands, of male bosses, of ruling men in most societal institutions, in politics and economics, in short, what has been called 'the men's league' or men's house (Mies, 1986). Moreover, the term 'patriarchy' denotes the historical and societal dimension of women's exploitation and oppression. Traces of this exploitation and oppression are 
rooted in the gender division of labor. Social origin of division largely based on biological differences between men and women. Where men work is viewed as human labor and women's work as a natural activity, so the relation between male (human) and female (natural) laborer is that of domination and exploitation. The man's work is considered more productive adding to the accumulation of capital but woman is taken as a consumer of this capital. Women's deprivation is based on this concept of sexual division of gender and gender division of labor.

Women being considered as born for reproduction and rearing of children are given less opportunities for education because it is not considered as essential for the kind of work women are assigned. Deprived with education and skills, employment or working opportunities, women also seem to be obscure from the public realm. Women have to be dependent upon men for the fulfillment of needs required for their survival. Thus the vicious circle of exploitation and oppression of women taking its root from gender division of labor strengthens women's deprivations in every orbit of their lives-public and private.

In similar fashion, it was assumed that in Pakistani society male were more powerful and its culture also gave more authority and freedom to male counterpart. Cultural restrictions on the mobility of women might limit their freedom to include themselves in social, economic and political life of society. Based on this framework, it was also assumed that women's inclusion in various fields was determined by the attitude of their male counterparts. Women can enjoy the inclusive approach where men possesses more egalitarian attitude towards gender profile in their families. Women's social exclusion was based on gender inequalities and dominant-subordination relationship of men and women. Often it was observed that culture specifies its gender sensitive roles for both men and women based on the needs and requirements of social structure.

With gendered specification of roles, inequalities and suppression of women are deep rooted as inherent characteristics of society. Women inculcate these inequalities as they are brought up and so these inequalities do not appear to them as alien or external to their personalities. Their personalities are molded and they accept their statuses defined by the society. Accordingly, their roles are described which are usually targeted with household activities. Women are made to learn those skills necessary to take up these roles and only those resources are provided which facilitate learning of these skills. The rest of the resources are kept and used by men. This is the basis from where discrimination of women is started and women are deprived of equal opportunities and resources.

\section{Objectives of the Study}

It was assumed that women's exclusion is determined by the attitude of men and resources of the family. If men of the household are literate and professionals' there are 
more chances for women to get involved in socio-economic life. Therefore, present study is intended to find out what are various determinants of social exclusion of women.

\section{Materials and Methods}

The present study was based on the household survey. Primary data for this study was collected from five villages and one urban community through administering individual and community level survey questionnaire. The data was gathered by interviewing 622 ever married women in both rural and urban areas in Kasur and Lahore district respectively.

Social exclusion of women was examined by certain independent variables: household income, husband education and occupation. Household income was assessed in Pakistani Rupees and four categories were used in this analysis. Husband literacy was gauged by asking a question whether respondent's husband had attended any regular school or Madrassa. Occupation of husband was determined by taking various professions: for instance, government-based employee, private-sector employee, business, agriculture and others. Social exclusion was measured categorically. Various indicators were taken into account to measure social exclusion of women. It was assessed by considering seven indicators: working outside the home for wages, engagement in business activities, vote casting, participation in festivals and fairs, participation in political activities, decision making in household, participation in religious gatherings. All these indicators were measured at two levels yes/ no. Score ranged from 0 to 7 . Respondents with $\leq 3$ were considered as less excluded and with $\geq 4$ as highly excluded.

\section{Results}

\section{Table 1}

Social Exclusion of Women by Husband's Occupation

\begin{tabular}{|l|c|c|c|}
\hline $\begin{array}{l}\text { Husband's main } \\
\text { occupation }\end{array}$ & \multicolumn{2}{|c|}{ Social Exclusion } & Total \\
\hline & Low & High & \\
\hline Govt. Employee & $75(68.8 \%)$ & $34(31.2 \%)$ & $109(100.0 \%)$ \\
\hline Private Employee & $145(69.0 \%)$ & $65(31.0 \%)$ & $210(100.0 \%)$ \\
\hline Own Business & $82(61.2 \%)$ & $52(38.8 \%)$ & $134(100.0 \%)$ \\
\hline Agriculture & $58(43.9 \%)$ & $74(56.1 \%)$ & $132(100.0 \%)$ \\
\hline Other & $35(50.0 \%)$ & $35(50.0 \%)$ & $70(100.0 \%)$ \\
\hline Total & $\mathbf{3 9 5}(\mathbf{6 0 . 3 \%})$ & $\mathbf{2 6 0 ( 3 9 . 7 \% )}$ & $\mathbf{6 5 5 ( 1 0 0 . 0 \% )}$ \\
\hline
\end{tabular}

Pearson Chi-square Value $=27.915$, $\mathrm{P}$-value $=.000$ 
It was assumed earlier that husband's occupation might have played an important role in determining the level of social exclusion of women. Therefore husband's 'type of occupation' was identified from the existent data and it was tried to find out that whether it affected women's social exclusion or not. Results were presented in Table 1 and data showed that women's level of social exclusion varied with respect to husband's occupation. Cross table showed that those females whose husbands were engaged in agricultural activities were highly excluded from the society. Those female whose husbands had any type of employment (Govt. or private) were less excluded as compared to the other categories. Chi. square test of association showed that status of social exclusion and profession of husband had strong association/relationship.

Table 2

Social Exclusion of Women by Husband Attendance of School/ Madrassa

\begin{tabular}{|l|c|c|c|}
\hline \multirow{2}{*}{$\begin{array}{l}\text { Husband Attendance of Regular } \\
\text { School/ Madrassa }\end{array}$} & \multicolumn{2}{|c|}{ Tocial Exclusion } & \multirow{2}{*}{ Total } \\
\hline & Low & High & \\
\hline Yes & $304(70.0 \%)$ & $130(30.0 \%)$ & $434(100.0 \%)$ \\
\hline No & $91(41.2 \%)$ & $130(58.8 \%)$ & $221(100.0 \%)$ \\
\hline Total & $\mathbf{3 9 5}(\mathbf{6 0 . 3 \%})$ & $\mathbf{2 6 0 ( 3 9 . 7 \% )}$ & $\mathbf{6 5 5}(\mathbf{1 0 0 . 0 \% )}$ \\
\hline
\end{tabular}

Pearson Chi-square Value $=50.984$,

$\mathrm{P}$-value $=.000$

It was discussed earlier that in patriarchal structure, women were excluded from main socio-economic stream of life and due to dominant-subordinate relationship based on gender discrimination. It was also assumed that husband's education could have influenced social exclusion of women. Plausible explanation of this assumption could be that education helped broaden the horizon of individuals that further helped give space to other individuals to exercise their potential. Based on this assumption, the social exclusion of women was analyzed with reference to their husband's education. As expected, it was found that significant majority of respondents (70\%) whose husband had attained formal schooling were less excluded. Similarly, among the category of highly excluded women, the majority of respondents $(58.8 \%)$ were those whose husband did not get any formal schooling.

Chi. Square value 50.984 also showed strong association/relationship between education status of husband and social exclusion of women. 
Table 3

Social Exclusion of Women by Household Income

\begin{tabular}{|l|c|c|c|}
\hline \multirow{2}{*}{$\begin{array}{l}\text { Household Income Per Month } \\
\text { In Pakistani Rs }\end{array}$} & \multicolumn{2}{|c|}{ Social Exclusion } & \multirow{2}{*}{ Total } \\
\hline & Low & High & \\
\hline$<=5000$ & $163(52.6 \%)$ & $147(47.4 \%)$ & $310(100.0 \%)$ \\
\hline $5001-10000$ & $136(63.3 \%)$ & $79(36.7 \%)$ & $215(100.0 \%)$ \\
\hline $10001-15000$ & $52(72.2 \%)$ & $20(27.8 \%)$ & $72(100.0 \%)$ \\
\hline $15001 \&$ Above & $44(75.9 \%)$ & $14(24.1 \%)$ & $58(100.0 \%)$ \\
\hline Total & $\mathbf{3 9 5}(\mathbf{6 0 . 3 \%})$ & $\mathbf{2 6 0 ( 3 9 . 7 \% )}$ & $\mathbf{6 5 5}(\mathbf{1 0 0 . 0 \%})$ \\
\hline
\end{tabular}

Pearson Chi-square Value $=18.664$,

$\mathrm{P}$-value $=.000$

Household income was another interesting determinant of social exclusion of women. It seemed from the data that women's social exclusion might be influenced with the level of household income. Data in the above Table indicated interesting findings that household income was a function of inclusion of women. It showed that with the increase of household income, social exclusion of women decreases. It was also observed that in the income category of Rs 1000-5000 half of women 47.4\% were excluded; whereas in category of Rs 15001 and above only one fourth (24.1\%) were excluded. Chi. Square test of association showed strong relationship between two variables.

\section{Discussion}

The analysis of the data suggested that women's social exclusion was determined by various factors for instance, education of husband, household income and occupation of husband. Keeping in view that in Pakistani society, household's and husband's status plays an important role in the lives of women, the future of women will be decided by the resources of the household as well as of husband. If the households have enough resources and high income levels, they can divert these resources on the socio-economic development of women. If household's resources are limited, then girls have to suffer by having only limited resources at their disposal for their socio-economic uplift in society. Similarly results of our findings suggested that with the increase in the income of the household women's social exclusion decreased proportionally.

Another aspect of our analysis was that husband's education and occupation seemed to influence the social exclusion of women. Results clearly indicated that those women whose husbands were government or private employee were not excluded; whereas women whose husbands were engaged in agricultural (traditional or agrarian mode of production) activities, were excluded from main socio-economic stream of life. This trend was vividly present in the rural areas of Pakistan. The results may imply that 
occupation influences the mind-set or orientation of men, allows them to broaden their horizon which may have impact on the lives of women. Husband may have more moderate views towards the life of women and allow them to integrate into the sociocultural fabric of society.

Majority of men with high level of education may be more inclined towards egalitarian configuration of power in gender-based relations. The educated background compels them to bring women in social reconstruction programs. Similarly, occupation also influences perception of men towards women. Type of occupation provides men with the opportunity of exposure with regard to participation of women in various fields. A person engaged in service sector is more inclined to nourish inclusive role of women in arena of economic activities as compared to traditional mode of production. Therefore, present study supported the argument that women's social exclusion is influenced by husbands and family socio-economic status.

\section{Conclusions}

The analysis of present study brings an important point to light that men's attitude plays an important role in making women socially excluded or not. As analysis suggests that women are less excluded from main socio economic stream of life where husband are literate or are employed in some private or Government sector, therefore the need is to change the orientation of men that can lead for an inclusive approach towards women. Two significant indicators to bring change in the attitude of men are education and type of employment. Both these indicators also seem to be reinforcing each other as education is prerequisite for white collar employment and similarly employed persons sometimes need to improve their qualifications if they want to go up in employment ladder.

To change a patriarchal structure and to make it an egalitarian society men's role cannot be ignored therefore need is to redirect orientations of men towards women' role in society at various levels for instance, household, community and national. Media could play an important role in molding the mind set of men by educating them how inclusive approach of women could be helpful for their families, community and society. Similarly the curriculum should be designed in such a way to make women inclusive in social and economic spheres of society. Civil society organizations should launch awareness programs for consolidation of women's position in the society. Individual efforts in unison with collective endevours can bring necessary changes in societal attitudes towards women. 


\section{References}

Amin, S., Mahmud, S. \& Huq, H. (2002). Baseline Survey Report On Rural Adolescents In Bangladesh, Dhaka: Ministry of Women's Affairs, Government of Bangladesh.

Barry, M. (2002). Social Exclusion Aand Social Work: An Introduction. London: Russell House Printing.

Brady, Martha. (2003). Safe Spaces For Adolescent Girls, in Adolescent and Youth Sexual and Reproductive Health: Charting Directions for a Second Generation of Programming (background documents). New York: UNFPA, pp, 155-176.

Burchardt, T. (2000). Social Exclusion: Concepts and Evidence, Bristol: The Policy Press.

Byrne, D. (2000). Social Exclusion. Buckingham: Open University Press.

Clark, S., Bruce, J. \& Annie, D. (2006). Protecting Young Women From HIV/AIDS: The Case Against Child And Adolescent Marriage, International Family Planning Perspectives, 32 (2): pp, 79-88.

Colom, R., Rebollo, I., Palacios, A., Juan-Espinosa, M. \& Kyllonen, P. C. (2004). Working Memory is (almost) Perfectly Predicted by G. Intelligence, 32: pp, 277-296.

Erulkar, Annabe,1. S., Mekbib, T., Simie, N. \& Gulema, T. (2004). The Experience Of Adolescence In Rural Amhara Region, Ethiopia. New York: Population Council.

Gordon, D., et.al. (2000). Poverty And Social Exclusion In Britain. York: Joseph Rowntree Foundation.

Howarth, C., Kenway. P., Palmer, G. \& Miorelli, R. (1999). Monitoring Poverty and Social Exclusion. York: Joseph Rowntree Foundation, York Publishing Service.

Jackson, C. (1999). Social Exclusion and Gender: Does one Size fit all? European Journal of Development Research, 11: pp, 125-146.

Kabeer, N. (2000). Social Exclusion, Poverty and Discrimination.IDS Bulletin 31: pp, 83-97.

Khan, S. (2010). Gender Inequality, Social Exclusion and Maternal \& Newborn Health, Research and Advocacy Fund. 
Kishor, S. \& Johnson, K. (2004). Reproductive Health and Domestic Violence: Are the Poorest Women Iniquely Disadvantaged? Demography, 43(2): pp, 293-307.

Mensch, B. S. (2005). The Transition to Marriage, in Cynthia B. Lloyd (ed.), Growing Up Global: The Changing Transitions to Adulthood in Developing Countries. Washington, DC.

Mensch, Barbara S., Bruce, J. \& Margaret, E. G. (1998). The Uncharted Passage: Girls' Adolescence in the Developing World. New York: Population Council.

Mensch, Barbara, S., Barbara, L., Ibrahim, Susan, M. L. \& El-Gibaly, O. (2003). GenderRole Attitudes Among Egyptian Adolescents. Studies in Family Planning, 34(1): 8-18.

Mies, M. (1986). Patriarchy And Accumulation On A World Scale: Women In The International Division Of Labor. Zed Books Ltd.

Narryan, D. (1999). Complementarity And Substitution: The Role of Social Capital, Civic Engagement and the State in Poverty Reduction. New York: World Bank. National Academies Press, pp, 416-505.

Robinson, P. \& Oppenheim, C. (1998). Social Exclusion Indicators, London: IPPR.

Room, G. (1995). Beyond the Threshold: The Measurement And Analysis Of Social Exclusion. Bristol: Policy Press.

Santhya, K.G. \& Shireen, J. J. (2003). Sexual And Reproductive Health Needs Oof Married Adolescent Girls, Economic and Political Weekly, 38(41): pp, 4370-4377.

Dr. Fauzia Maqsood is Assistant Professor in the Department of Sociology, University of Gujrat, Pakistan.

Dr. Mohammad Nizamuddin is Vice Chancellor of University of Gujrat. He is HEC Professor in the Department of Sociology, University of Gujrat, Pakistan. 